\title{
SISTEMA ROBÓTICO DE BAIXO CUSTO PARA PREPARAÇÃO DE FILMES POR LAYER-BY-LAYER
}

\author{
Giovanne Santin Polo ${ }^{\mathrm{b}}$, Lucas Polimante Souto ${ }^{\mathrm{a}}$ e André Sarto Polo ${ }^{\mathrm{a}, *, 10}$ \\ ${ }^{a}$ Centro de Ciências Naturais e Humanas, Universidade Federal do ABC, 09210-580 Santo André - SP, Brasil

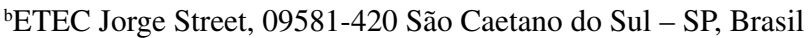

Recebido em 19/02/2021; aceito em 08/04/2021; publicado na web em 06/05/2021

\begin{abstract}
LOW-COST ROBOTIC SYSTEM FOR PREPARATION OF LAYER-BY-LAYER FILMS. Layer-by-Layer is an efficient technique for the deposition of thin films used in several devices such as sensors, solar cells, and other systems. A robotic system improves the process reproducibility, be a stand-alone system, and does not demand human participation during the deposition process. On the other hand, the commercially available equipment is expensive. In this work, we present a low-cost robotic system built by using materials commonly found that allows performing several bathing, drying steps and deposition cycles of the substrates necessary for the formation of LbL films. This technical note presents the electronic assembly scheme and the program developed for an experiment. The number of baths, the time necessary for the deposition, and repetitions to result in the formation of the desired film; can be easily modified in this program. The films prepared in this experiment were successfully employed for the preparation of compact layers for perovskite solar cells. Therefore, the equipment can be easily customized to the needs of each research group that uses it.
\end{abstract}

Keywords: Automated Layer-by-Layer deposition; low-cost equipment; compact layers preparation.

\section{INTRODUÇÃO}

A técnica de deposição de materiais por camadas, conhecida como Layer-by-Layer, LbL, tem sido muito utilizada para a preparação de filmes automontados e é baseada na sobreposição de camadas de materiais que tem algum tipo de afinidade, como por exemplo cargas opostas, polaridade similar, interações hidrofóbicas, interações por ligação de hidrogênio, interações biológicas específicas, entre outras. ${ }^{1}$ Esse é um procedimento bastante interessante para a preparação de filmes a serem usados em dispositivos de conversão de energia, ${ }^{2-4} \mathrm{em}$ biossensores, ${ }^{5,6}$ em supercapacitores, ${ }^{7,8}$ em sensores de umidade, ${ }^{9}$ ou ainda em aplicações biomédicas. ${ }^{10,11}$ É uma técnica simples e com grande reprodutibilidade que possibilita o controle da espessura dos filmes através do número de camadas depositadas de materiais, o que permite um controle fino em sistemas que demandem a formação de uma camada compacta e com espessura definida.

A preparação de filmes por LbL envolve a imersão de um substrato em solução do material a ser depositado, ou seu precursor, por um determinado tempo, seguido da sua secagem e posterior imersão em outros solventes e/ou soluções. A etapa de secagem é importante pois permite que a camada depositada tenha sua adesão total à camada anteriormente depositada e que a sua superfície fique pronta para a próxima deposição, evitando processos de remoção da camada, com a lixiviação. Dessa maneira, ocorre uma melhor adesão dos filmes aos substratos, fazendo com que a deposição seja efetiva. Depois que o substrato é submetido a todas as deposições e secagens, finaliza-se um ciclo. Os substratos podem passar por vários ciclos de deposição para atingir a espessura desejada. Dependendo das condições utilizadas, a preparação de um filme pode levar várias horas, o que motiva a utilização de um sistema automatizado. Existem no mercado alguns sistemas robóticos para realizar esse tipo de deposição, porém, seu custo pode ser um fator restritivo em diversos casos, uma vez que que esse tipo de equipamento pode custar cerca de $£ 1,800$, sem considerar as despesas de transporte e importação. ${ }^{12}$ Os sistemas comerciais possuem um controle muito preciso de todas as etapas do processo, como, por exemplo, as velocidades de inserção e remoção

*e-mail: andre.polo@ufabc.edu.br de substratos em soluções, além dos tempos que os substratos ficam imersos, etc. Contudo, em diversas deposições não há necessidade de tamanha precisão, elas demandam apenas um sistema que permita realizar diferentes ciclos de deposição, de maneira repetitiva, o que permite que o processo seja facilmente automatizado.

Alguns sistemas desenvolvidos em laboratório para automatizar as deposições já foram publicados previamente..$^{13,14}$ Os sistemas descreviam a utilização de motores de passos e materiais específicos, como o corpo de um microscópio que nem sempre é disponível, e demandavam que o sistema ficasse conectado a um microcomputador pelo cabo de impressora por uma porta paralela durante todo o processo de deposição.

Atualmente existem novos componentes disponíveis no mercado para substituir esses sistemas. A plataforma open-source Arduino é um exemplo disso. Ele pode controlar motores de maneira bastante precisa e utiliza conexões mais atuais e disponíveis em microcomputadores, como as portas USB. Isso é bastante interessante, pois os microcomputadores atuais já não possuem mais portas paralelas. Além disso, o Arduino utiliza uma linguagem de programação bastante simples e que permite o armazenamento da programação na memória do microcontrolador. A utilização de microcontroladores como esse permite que o sistema não necessite de um microcomputador conectado o tempo todo da deposição. Além dos controladores, braços mecânicos robóticos são facilmente encontrados no mercado com preços acessíveis, e são uma excelente alternativa à improvisação ou adaptação de partes de outros equipamentos.

Este trabalho insere-se neste contexto e apresenta a proposta da adaptação de um braço robótico de baixo custo para a preparação de filmes por LbL onde seja necessária a repetição das etapas da deposição e secagem do material para a formação dos filmes. ${ }^{15-18}$ Propõe-se também um programa base para o controle das etapas de deposição, sendo possível utilizar até quatro béqueres. O programa proposto é de código aberto e pode ser facilmente modificado pelo usuário para adequar às necessidades de cada grupo de pesquisa.

\section{MATERIAIS E MÉTODOS}

O braço robótico utilizado (MingWu Electronics - 100 x 200 mm 
e de até $180^{\circ}$ de rotação sobre seu eixo) possui quatro servo motores, que podem ser comandados independentemente pelo programa de controle. Utilizou-se um Arduino Mega 2560 para controlar o braço robótico. As ligações elétricas foram feitas em uma placa de testes e protótipo (protoboard) para conectar cada um dos servomotores às saídas lógicas do Arduino e para que eles fossem alimentados com eletricidade $(5 \mathrm{~V})$. Também foi incluído no sistema um display LCD (16 caracteres x 2 linhas) que mostra em qual ciclo o robô está trabalhando, ao final do processo é apresentada uma mensagem de término das deposições.

Para verificar o funcionamento do braço robótico, foram preparados filmes compactos de $\mathrm{TiO}_{2}$ sobre substratos de FTO (Fluorine-doped Tin Oxide coated glass - Vidro recoberto com óxido de estanho dopado com flúor), utilizando meios ácido e básico, como é descrito na literatura. ${ }^{3}$ Em resumo, um substrato é mergulhado em uma solução ácida de $\mathrm{TiO}_{2}$ por 5 minutos seguido da lavagem em água deionizada por 2 minutos e posterior secagem ao ar por mais 5 minutos. Após essa secagem, o substrato é mergulhado em solução básica de $\mathrm{TiO}_{2}$ por 5 minutos, lavado em água por mais 2 minutos e seco ao ar por mais 5 minutos, completando assim um ciclo de deposição (Figura 1). Usando esse procedimento, foram preparadas amostras com 5, 10, 15, 20 e 30 ciclos de deposição.

O tratamento prévio dos substratos de FTO bem como a preparação e deposição da perovskita e as medidas de fotoluminescência dos dispositivos estão descritas na literatura. ${ }^{3}$

\section{RESULTADOS E DISCUSSÃO}

A montagem mecânica do braço robótico seguiu a indicação do fabricante. Uma haste metálica com um grampo de papel foi adaptada na garra do braço robótico para facilitar a fixação do substrato usado. Por fim, o braço robótico foi colocado sobre uma base (nesse caso, um suporte de tubos de ensaio) para que atingisse a altura adequada para inserir e remover as amostras dos béqueres. Após a montagem mecânica, foram feitas as conexões elétricas e lógicas como mostradas na Figura 2. Um dos servomotores, originalmente responsável pelo movimento de abrir e fechar a garra, não foi utilizado na montagem e, por isso, ele não é mostrado no esquema.

Cada um dos servomotores foi usado para realizar um movimento do braço robótico utilizado, sendo um deles utilizado para realizar o movimento vertical, tornando possível a inserção e a remoção do substrato nas soluções. Outro motor foi utilizado para realizar

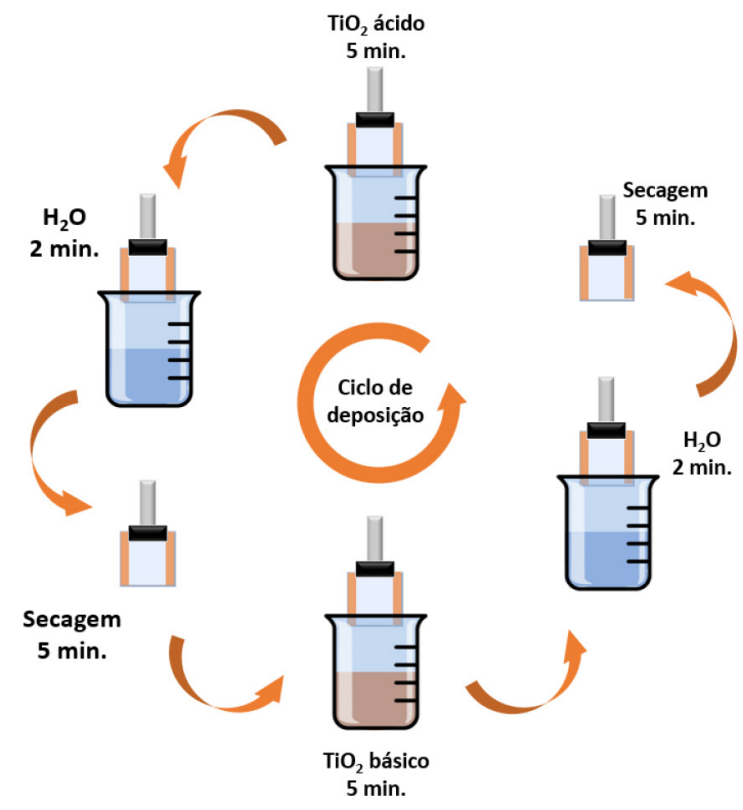

Figura 1. Esquema dos ciclos de deposição em diferentes soluções para a formação dos filmes de $\mathrm{TiO}_{2}$

o movimento de rotação de todo o sistema, tornando possível a movimentação do substrato entre os béqueres em cada etapa. E, por fim, um motor foi responsável por ajustar o ângulo de inclinação da ponta do braço mecânico evitando que o substrato colidisse com o béquer ou com o próprio sistema do braço robótico durante a sua movimentação. Eles foram definidos no programa como meuServo, meuServo1 e meuServo2.

Para deixar o sistema mais refinado, foi adicionado um display LCD, que indica qual fase do processo está sendo executada (por exemplo: ciclo 1/10), facilitando o monitoramento do processo. Para isso, foram feitas as conexões ao display onde é necessário adicionarse um potenciômetro para ajustar o contraste do display de LCD, permitindo a sua leitura.

O Arduino pode ser conectado diretamente ao computador por um cabo USB. Uma vez que o programa é carregado no Arduino, uma simples fonte de carregador de bateria de celular pode fornecer a alimentação elétrica necessária para que o sistema opere sem a necessidade de estar conectado ao microcomputador. Foi colocado

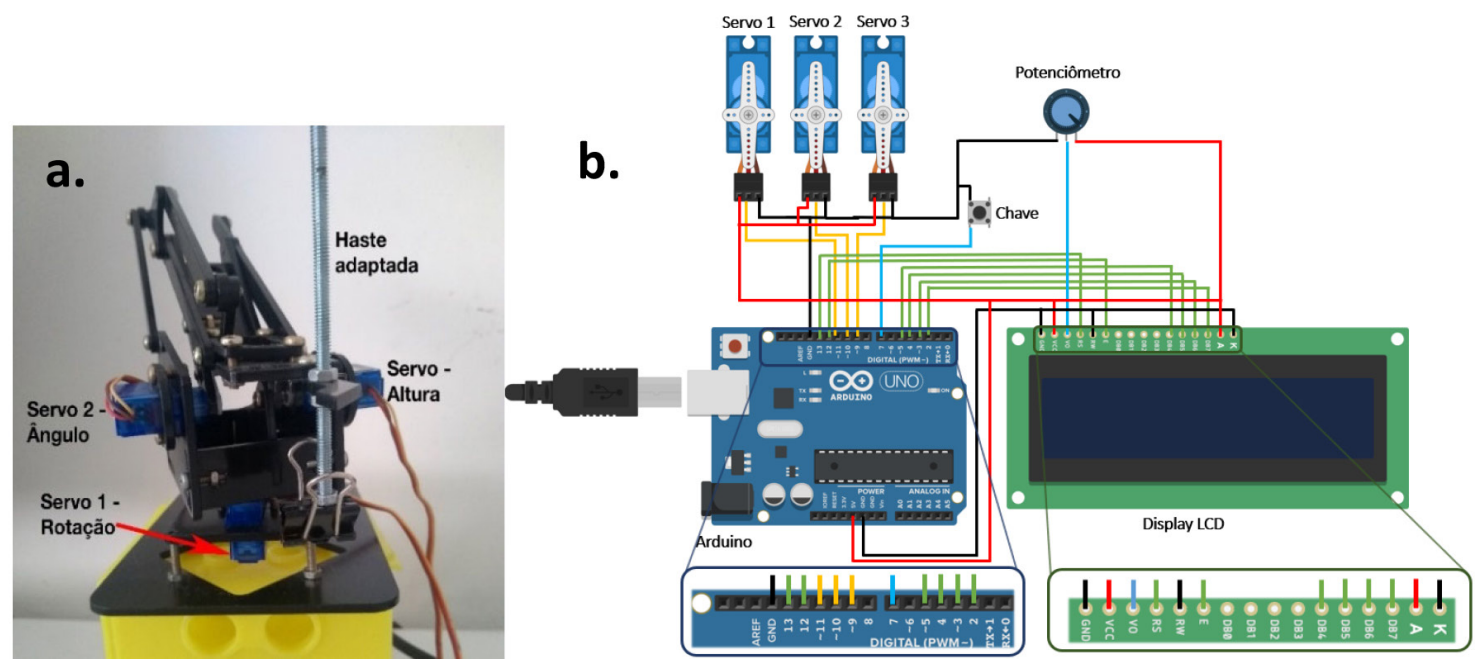

Figura 2. a. Foto do braço robótico montado com os respectivos servomotores e adaptação feita para fixar os substratos. b. Esquema das ligações elétricas e lógicas do braço robótico. No diagrama, as linhas vermelhas indicam o polo elétrico positivo, as pretas o negativo, as laranjas as conexões lógicas para acionamento dos servos e as verdes as conexões lógicas para o display LCD 
no circuito um interruptor para iniciar a operação autônoma, ou seja, quando o sistema não estiver conectado ao microcomputador.

O programa de controle desenvolvido é bastante simples e baseiase nos ângulos que os servomotores atuam. Variando-se esses ângulos, é possível fazer as movimentações necessárias para as deposições. No exemplo disponibilizado, o programa é comentado linha a linha, possibilitando facilmente a identificação dos parâmetros como os tempos de banhos e os ângulos de posição entre os béqueres, o que permite personalizar o uso deste braço robótico através de modificações simples na programação. Esse programa foi feito para realizar um experimento com quatro banhos distintos, utilizando béqueres de $50 \mathrm{~mL}$ posicionados sobre uma superfície. A variação de $20^{\circ}$ de rotação no servomotor (meuServo1) foi adequada para que o braço se posicionasse corretamente sobre cada béquer. Caso sejam utilizados recipientes com diâmetros diferentes, este parâmetro deve ser ajustado.

A altura que o substrato foi mergulhado nos banhos foi controlada tanto pelo ângulo do servomotor (meuServo), como pelo volume de solução que foi colocada em cada um dos béqueres. Procurouse adicionar o mesmo volume de solução para todos os béqueres. Os tempos (programados em milissegundos) de cada banho ou de cada secagem, também são personalizáveis. Recomenda-se que inicialmente sejam verificadas todas as posições e alturas para a realização do experimento. Para essa verificação, é interessante diminuir os tempos de banho e secagem para que o processo seja mais rápido e que os béqueres, ainda vazios, sejam posicionados onde serão utilizados. Feito isso, o operador inicia o processo com um substrato que possa sofrer algum dano, pois nessa etapa podem ocorrer acidentes e quebras. Uma vez que o sistema estiver ajustado, não existe mais a necessidade de mantê-lo conectado ao computador.

No experimento usado como modelo, foram feitas todas as etapas descritas e prepararam-se camadas compactas de $\mathrm{TiO}_{2}$ que foram utilizadas em um trabalho sobre células solares de perovskitas, que foi recentemente publicado. ${ }^{3} \mathrm{O}$ tempo de cada ciclo de deposição é de 24 minutos, fazendo com que as camadas levassem de 2 a 12 horas para serem depositadas, dependendo do número de ciclos de deposição. Considerando esse tempo total de deposição, é plenamente justificável o uso de um sistema automático para substituir um operador.

As camadas compactas preparadas foram usadas em um experimento para avaliar a recombinação de elétrons em células solares de perovskitas, utilizando a técnica de espectroscopia de fotoluminescência. ${ }^{3} \mathrm{Na}$ situação apresentada, espera-se que quanto maior seja a recombinação do par elétron-buraco gerado, mais intensa seja a emissão de luz. A camada de $\mathrm{TiO}_{2}$ depositada por $\mathrm{LbL}$ tem a função de manter o elétron e o buraco separados, evitando a sua recombinação e, portanto, diminuindo a intensidade de emissão conforme aumenta-se a sua espessura. Observou-se que o aumento de ciclos de deposição leva ao aumento da espessura do material formado e, consequentemente, levando a uma diminuição da recombinação de elétrons, indicado pelo menor valor de intensidade de emissão. Porém, ao continuar aumentando a espessura do material, a camada passa a impedir a injeção de elétrons no circuito externo, aumentando a recombinação do par elétron-buraco e a fotoluminescência volta a aumentar. (Figura 3). Os dados são compatíveis com o aumento da espessura das camadas, como é discutido no artigo, e com os filmes preparados utilizando um equipamento comercial de deposição, mostrando que esse sistema tem um desempenho idêntico ao equipamento comercial.

Esse sistema é bastante útil para deposições de materiais por LbL em substratos que necessitam apenas de diferentes banhos e secagens por tempos definidos, bem como repetição de ciclos. É um sistema extremamente atraente pela facilidade de programação, de possibilidades de adaptação e de uso em diversas situações. Por ser

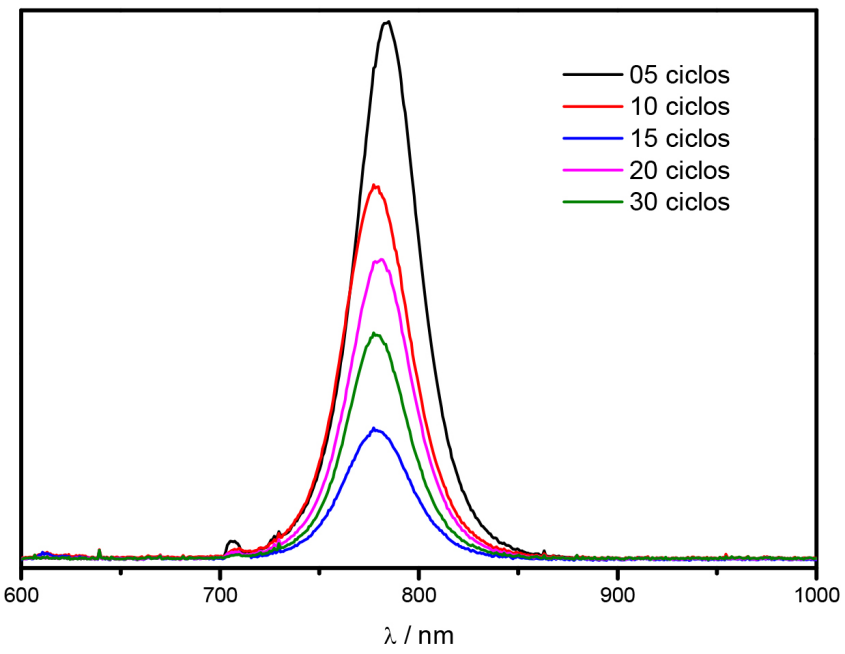

Figura 3. Intensidade de emissão de filmes de perovskitas depositados sobre camadas de $\mathrm{TiO}_{2}$ preparadas por diferente número de ciclos realizados pelo braço robótico proposto. Reproduzido da ref. 3 Copyright (2021), com permissão da Elsevier

um sistema com software livre, ele pode ser modificado de acordo com as necessidades do usuário e ainda pode ser personalizado por cada um. Ainda existe a possibilidade de substituir a protoboard por uma placa de circuito impresso de maneira a diminuir as chances de realizar conexões erradas por parte do usuário final. Essas são apenas algumas melhorias que poderão ser incorporadas a esse braço robótico.

\section{CONCLUSÕES}

Nesta nota técnica apresentou-se a adaptação de um braço robótico para a preparação de filmes através da técnica de Layer-by-Layer. Essa proposta permite a realização dos experimentos que necessitam de repetições nos processos de deposição dos materiais para a formação dos filmes, com a utilização de materiais e componentes de baixo custo. A versatilidade e adaptabilidade do sistema permite que qualquer grupo de pesquisa possa usar e personalizar essa proposta em uma ampla gama de aplicações.

\section{MATERIAL SUPLEMENTAR}

O programa desenvolvido nessa proposta está disponível em http://quimicanova.sbq.org.br, na forma de arquivo do Arduino, com acesso livre. Um vídeo mostrando o equipamento em funcionamento está disponível em https://youtu.be/-Nnt-Vml-cg.

\section{AGRADECIMENTOS}

Os autores agradecem o apoio financeiro recebido da FAPESP (2019/23277-4) e agradecem também ao PRH-ANP, pela bolsa de L. P. Souto.

\section{REFERÊNCIAS}

1. Borges, J.; Mano, J. F.; Chem. Rev. 2014, 114, 8883.

2. Nunes, B. N.; Paula, L. F.; Costa, Í. A.; Machado, A. E. H.; Paterno, L. G.; Patrocinio, A. O. T.; J. Photochem. Photobiol., C 2017, 32, 1.

3. Veiga, E. T.; Fernandes, S. L.; Graeff, C. F.d. O.; Polo, A. S.; Solar Energy 2021, 214, 510.

4. Nascimento, L. L.; Brussasco, J. G.; Garcia, I. A.; Paula, L. F.; Polo, A. S.; Patrocinio, A. O. T.; J. Phys.: Condens. Matter 2020, 33, 055002. 
5. Amorim, S.; Soares da Costa, D.; Mereiter, S.; Pashkuleva, I.; Reis, C. A.; Reis, R. L.; Pires, R. A.; Mater. Sci. Eng. C 2021, 119, 111616.

6. Ghanei Agh Kaariz, D.; Darabi, E.; Elahi, S. M.; J. Theor. Appl. Phys. 2020, 14, 339.

7. Fávero, V. O.; Oliveira, D. A.; Lutkenhaus, J. L.; Siqueira, J. R.; J. Mater. Sci. 2018, 53, 6719.

8. Li, Z.; Wang, J.; Liu, X.; Liu, S.; Ou, J.; Yang, S.; J. Mater. Chem. 2011 $21,3397$.

9. Zhang, D.; Zong, X.; Wu, Z.; Zhang, Y.; Sensor. Actuat. B: Chem. 2018, $266,52$.

10. Guo, S.; Zhu, X.; Loh, X. J.; Mater. Sci. Eng. C 2017, 70, 1163.

11. Akiba, U.; Minaki, D.; Anzai, J. I.; Polymers 2017, 9.
12. https://www.ossila.com/products/dip-coater?variant $=8806311133301$, acessada em outubro 2020.

13. Oliveira, A. R. M.; Zarbin, A. J. G.; Quim. Nova 2005, 28, 141.

14. Trivinho-Strixino, F.; Lopes, C. L. R.; Pereira, E. C.; Quim. Nova 2004, $27,661$.

15. Teixeira, P. R.; Machado, T. R.; Machado, F.; Sodré, F. F.; Silva, J. G.; da Silveira Neto, B.; Paterno, L. G.; Microchem. J. 2020, 152, 104421.

16. Peregrino, P. P.; Cavallari, M. R.; Fonseca, F. J.; Moreira, S. G. C.; Sales, M. J. A.; Paterno, L. G.; ACS Omega 2020, 5, 5001.

17. Soler, M. A. G.; J. Magn. Magn. Mater. 2018, 467, 37.

18. Wang, C.; Shen, M.; Ding, Y.; Zhao, D.; Cui, S.; Li, L.; J. Electroanal. Chem. 2017, 785, 131. 